\title{
EDITORIAL
}

\section{Computed tomography and monitoring of emphysema}

\author{
H.O. Coxson
}

I $t$ is well known that there have been no successful therapeutic interventions for subjects with emphysema. In the 1990s, investigators became very interested in lung volume reduction surgery (LVRS), first described by BRANTIGAN and MUELLER [1] in 1957, as a treatment for severe emphysema. While many sites promoted the use of LVRS for severe emphysema the criteria for the selection of patients, the effects on mortality and the magnitude and durability of benefits were not well established [2]. It was for these reasons that the National Emphysema Treatment Trial (NETT) was formed in the USA. While the first report from this study was bleak and warned that subjects who have a low forced expiratory volume in one second and either homogeneous emphysema or a very low diffusing capacity of the lung for carbon monoxide (DL,CO) had a high risk of dying after this procedure [3], the end results of the study did show that in a select population (upper-lobe patients with low exercise capacity) there was a benefit [2], which persisted for several years [4]. The investigators concluded that the effects of LVRS are durable, that it can be recommended for upper-lobe-predominant emphysema patients with low exercise capacity and that it should be considered for palliation in patients with upper-lobe emphysema and high exercise capacity [4]. One of the key factors in the outcome of these studies was the location of the emphysema, as described using computed tomography (CT).

CT has become the imaging device of choice for organs such as the lung as it provides physicians with an image of the lung which is very similar to that seen using gross pathology. The removal of overlapping structures commonly seen in standard chest radiography and the relatively good spatial resolution, particularly using the modern multi-detector row CT scanners, has positioned $\mathrm{CT}$ at the forefront of clinical imaging. However, the biggest advantage that $\mathrm{CT}$ gives investigators is that at its heart CT is a densitometry device. Therefore, a quantitative CT assessment of the lung not only provides investigators with spatial information about larger structures within the lung but, through densitometry, inferences about the microstructure of the tissue and airspace can be drawn. Early studies in LVRS using quantitative CT reported that CT measurements of the extent and location of emphysema could be used as a surrogate marker of response to intervention [5-9].

STATEMENT OF INTEREST: A statement of interest for H.O. Coxson can be found at www.erj.ersjournals.com/misc/statements.shtml

CORRESPONDENCE: H.O. Coxson, Dept of Radiology, Vancouver General Hospital, 855 West 12th Ave, Room 3350 JPN, Vancouver, V5Z 1M9, Canada. Fax: 1 6048754319. E-mail: Harvey.Coxson@vch.ca
However, as LVRS is for patients with very severe disease it is important to be able to quantify changes in lung structure with milder interventions and it is hoped that CT will provide just such a tool.

Many investigators are interested in using CT to quantify the changes of the lung in response to therapy. In the current issue of the European Respiratory Journal one of these groups, STOLK et al. [10], has applied quantitative CT techniques to assess the distribution of emphysema in "normal" subjects, emphysematous subjects with radiologist-assigned apical, basal or homogeneous distribution of disease and severe subjects undergoing LVRS. Once the baseline measurements were established, the investigators measured the changes in lung density in the subjects with very severe emphysema in response to LVRS. The investigators chose to study LVRS because this intervention is known to have outcomes that are quantifiable using the standard clinical and physiological techniques and because they can assess this intervention in a large number of subjects 3 months after the procedure, possibly a shorter time-frame than in other interventions in less severe disease. The results of the study show that the percentile method can be used to assess differences of disease distribution between normal subjects and subjects with emphysema, and that there is a change in the lung density following LVRS that correlates measurements of DL,CO and residual volume.

Quantitative CT analysis completely relies on the fact that the lung absorbs X-rays in direct correlation to the density of the lung tissue present [11]. Therefore, while the normal human lung has a symmetrical distribution of $X$-ray attenuation values around a mean of approximately $-800 \mathrm{HU}$, changes in the quantity of tissue and gas in the lung will cause changes in both the shape of this distribution and the percentage of lung voxels with a given $\mathrm{X}$-ray attenuation value. There are two common methods to quantify emphysema using densitometry, the first technique developed by MüLLER et al. [12] in the 1980s applied a pre-defined threshold, or "density mask" to the X-ray attenuation curve and showed that any voxels beyond this cut-off were "emphysematous" [12-17]. The second technique, pioneered by investigators in Edinburgh (UK) is similar but works in the opposite fashion, whereby a specific percentile value, initially the lowest 5th percentile, correlated with the extent of emphysema [18, 19]. DIRKSEN et al. [20] modified this approach and showed that the lowest 15th percentile was a reliable estimate of the extent of disease and that, while not statistically significant, this estimate of emphysema would be more powerful for use in interventional studies than standard physiological measurements of lung function. Both of these techniques have been used successfully in the past to quantify changes in the lung density in subjects undergoing $\operatorname{LVRS}[7,8,17,21]$. 
However, it is becoming increasingly well known that quantifying the extent of the disease is only part of the solution. Other studies have suggested that measures of emphysematous hole size [22] and distribution may be important, particularly in LVRS [17]. These early studies have recently been confirmed in NETT, whose authors conclude that apical distribution of large lesions, either assessed by a trained radiologist or quantified using these techniques, has a positive correlation with outcome following surgery [9].

The second finding by STOLK et al. [10], which has been investigated by this group before as well as others, is that the CT scan technique is very important in the assessment of emphysema. The authors note that there was a systematic difference in the density measurements between the subjects at two different institutions. As research into this field continues, it is becoming apparent that all factors of the CT scan must be either controlled, or at the very least accounted for. For example, STOEL et al. [23] showed previously that when using properly calibrated CT scanners lung densitometry values are very reproducible. However, in another study PARR et al. [24] showed that CT scanners are not always as well calibrated as people would like to think and that this can produce differences in lung density measurements over time that are not due to disease activity or intervention but to the CT scan technique. BOEDEKER et al. [25] also showed that the reconstruction algorithm used to create the CT images could make up to a $15 \%$ difference in the apparent extent of emphysema. A recent paper by MADANI et al. [26] showed that there were significant effects on the measurements of emphysema when either the CT slice thickness or the X-ray dose was changed. The conclusion of that paper was that while there were good correlations between the CT estimates of emphysema and the morphometric estimates, even at low dose the CT parameters cannot be changed between successive CT scans. It is important to keep in mind that, whether the investigator is using a threshold or a percentile analysis, these assessments are based on the shape of the X-ray attenuation distribution. Any factor that has an effect on the shape of this curve will effect the measurement of emphysema. The shape of this curve is dependent on the signal-to-noise ratio within the image and even simple things, such as increasing the spatial resolution of the reconstruction or decreasing the $\mathrm{X}$-ray dose, will increase the noise and therefore have an effect on the measurement of emphysema. These are factors that investigators have long known about, but they are now becoming more important as studies move from being smaller in sample size and located within one institution to being large in number and taking place in numerous institutions around the world. Furthermore, it is important to keep in mind the radiation burden to the subject imparted by serial CT scans, especially for research purposes. While it is true that a higher X-ray dose will produce a better-looking image, the data concerning emphysema is just as valid using the low-dose protocol. Therefore, as MADANI et al. [26] showed there is no reason why low-dose CT scans cannot be used, and in fact should be used, for serial measurements of emphysema, but the CT parameters must not be changed between scans. It must always be remembered that a CT scan is a measurement tool and should be used as such with all the careful consideration that goes into all measuring devices. When attention is paid to the details of the technique, there should be no reason why useful values should be available.

In conclusion, it is important that a sensitive technique be used to quantify small changes in the lung parenchyma that allow investigators to follow the progression of disease or quantify changes due to interventions. Quantitative computed tomography analysis of lung density is a powerful technique to assess emphysema and holds great promise to act as a noninvasive surrogate outcome parameter for studies of both pathogenesis and treatment.

\section{REFERENCES}

1 Brantigan O, Mueller E. Surgical treatment of pulmonary emphysema. Am Surg 1957; 23: 789-804.

2 Fishman A, Martinez F, Naunheim K, et al. A randomized trial comparing lung-volume-reduction surgery with medical therapy for severe emphysema. N Engl J Med 2003; 348: 2059-2073.

3 National Emphysema Treatment Trial Research Group. Patients at high risk of death after lung-volume-reduction surgery. N Engl J Med 2001; 345: 1075-1083.

4 Naunheim KS, Wood DE, Mohsenifar Z, et al. Long-term follow-up of patients receiving lung-volume-reduction surgery versus medical therapy for severe emphysema by the National Emphysema Treatment Trial Research Group. Ann Thorac Surg 2006; 82: 431-443.

5 Bae KT, Slone RM, Gierada DS, Yusen RD, Cooper JD. Patients with emphysema: quantitative CT analysis before and after lung volume reduction surgery. Work in progress. Radiology 1997; 203: 705-714.

6 Becker MD, Berkmen YM, Austin JH, et al. Lung volumes before and after lung volume reduction surgery: quantitative CT analysis. Am J Respir Crit Care Med 1998; 157: 1593-1599.

7 Gierada DS, Yusen RD, Pilgram TK, et al. Repeatability of quantitative CT indexes of emphysema in patients evaluated for lung volume reduction surgery. Radiology 2001; 220: $448-454$.

8 Rogers RM, Coxson HO, Sciurba FC, Keenan RJ, Whittall KP, Hogg JC. Preoperative severity of emphysema predictive of improvement after lung volume reduction surgery: use of CT morphometry. Chest 2000; 118: 1240-1247.

9 Martinez FJ, Foster G, Curtis JL, et al. Predictors of mortality in patients with emphysema and severe airflow obstruction. Am J Respir Crit Care Med 2006; 173: 1326-1334.

10 Stolk J, Versteegh MIM, Montenij LJ, et al. Densitometry for assessment of effect of lung volume reduction surgery for emphysema. Eur Respir J 2007; 29: 1138-1143.

11 Hedlund LW, Vock P, Effmann EL. Evaluating lung density by computed tomography. Sem Res Med 1983; 5: 76-87.

12 Müller NL, Staples CA, Miller RR, Abboud RT. “Density mask". An objective method to quantitate emphysema using computed tomography. Chest 1988; 94: 782-787.

13 Gevenois PA, de Maertelaer V, De Vuyst P, Zanen J, Yernault JC. Comparison of computed density and macroscopic morphometry in pulmonary emphysema. Am J Respir Crit Care Med 1995; 152: 653-657. 
14 Gevenois PA, De Vuyst P, de Maertelaer V, et al. Comparison of computed density and microscopic morphometry in pulmonary emphysema. Am J Respir Crit Care Med 1996; 154: 187-192.

15 Madani A, Zanen J, de Maertelaer V, Gevenois PA. Pulmonary emphysema: objective quantification at multidetector row CT - comparison with macroscopic and microscopic morphometry. Radiology 2006; 238: 1036-1043.

16 Coxson HO, Rogers RM, Whittall KP, et al. A quantification of the lung surface area in emphysema using computed tomography. Am J Respir Crit Care Med 1999; 159: 851-856.

17 Coxson $\mathrm{HO}$, Whittall KP, Nakano Y, et al. Selection of patients for lung volume reduction surgery using a power law analysis of the computed tomographic scan. Thorax 2003; 58: 510-514.

18 Hayhurst MD, Flenley DC, McLean A, et al. Diagnosis of pulmonary emphysema by computerized tomography. Lancet 1984; 2: 320-322.

19 Gould GA, MacNee W, McLean A, et al. CT measurements of lung density in life can quantitate distal airspace enlargement - an essential defining feature of human emphysema. Am Rev Respir Dis 1988; 137: 380-392.

20 Dirksen A. A randomized clinical trial of $\alpha_{1}$ antitrypsin augmentation therapy. Am J Respir Crit Care Med 1999; 160: 1468-1472.
21 Nakano $\mathrm{Y}$, Coxson $\mathrm{HO}$, Bosan $\mathrm{S}$, et al. Core to rind distribution of severe emphysema predicts outcome of lung volume reduction surgery. Am J Respir Crit Care Med 2001; 164: 2195-2199.

22 Mishima M, Hirai T, Itoh $\mathrm{H}$, et al. Complexity of terminal airspace geometry assessed by lung computed tomography in normal subjects and patients with chronic obstructive pulmonary disease. Proc Natl Acad Sci USA 1999; 96: 8829-8834.

23 Stoel BC, Bakker ME, Stolk J, et al. Comparison of the sensitivities of 5 different computed tomography scanners for the assessment of the progression of pulmonary emphysema: a phantom study. Invest Radiol 2004; 39: 1-7.

24 Parr DG, Stoel BC, Stolk J, Nightingale PG, Stockley RA. Influence of calibration on densitometric studies of emphysema progression using computed tomography. Am J Respir Crit Care Med 2004; 170: 883-890.

25 Boedeker KL, McNitt-Gray MF, Rogers SR, et al. Emphysema: effect of reconstruction algorithm on CT imaging measures. Radiology 2004; 232: 295-301.

26 Madani A, De Maertelaer V, Zanen J, Gevenois PA. Pulmonary emphysema: radiation dose and section thickness at multidetector CT quantification - comparison with macroscopic and microscopic morphometry. Radiology 2007; 243: 250-257. 